\title{
A Probabilistic Approach to Fatigue Design of Aerospace Components by Using the Risk Assessment Evaluation
}

\author{
Giorgio Cavallini and Roberta Lazzeri \\ University of Pisa-Department of Aerospace Engineering
}

Italy

\section{Introduction}

Fatigue design of aerospace metallic components is carried out by using two methodologies: damage tolerance and safe-life. At present, regulations mainly recommend the use of the former, which entrusts safety to a suitable inspections plan. Indeed, a crack or a flaw is supposed to have been present in the component since the beginning of its operative life, and it must remain not critical, i.e. it must not cause a catastrophic failure in the life period between two following inspections, (Federal Aviation Administration, 1998; Joint Aviation Authorities, 1994; US Department of Defence, 1998). When a crack is detected, the component is repaired or substituted and the structural integrity is so restored.

If the damage tolerance criterion cannot be applied, the regulations state the safe-life criterion should be used, i.e. components must remain free of crack for their whole operative life and, at their ends, components must be in any case substituted.

Therefore, both methodologies have deterministic bases and a single value (usually the mean value) is associated to each parameter that can influence the fatigue phenomenon, which on the contrary has a deep stochastic behaviour.

To take these items into account and in order to protect against unexpected events, it is necessary to introduce safety factors in the fatigue life design (generally equal to 2 or 3 for damage tolerance and equal to 4 or even more for safe-life). They usually produce heavy or expensive structures and, in the past, they were not always able to protect against catastrophic failures, because the real risk level is in any case unknown. On the one hand, indeed, the inspected structures or the substituted components may be still undamaged, with high costs; on the other hand, highly insidious phenomena, such as Multiple Site Damage and Widespread Fatigue Damage (which are typical of ageing aircrafts) cannot be taken into account very well and in the past they were the causes of some catastrophic accidents.

For these reasons, researchers are hypothesizing the possibility of facing fatigue design in a new way, by using the risk evaluation from a probabilistic point of view. Indeed, the parameters that affect the phenomenon have a statistical behaviour, and this can be described by means of statistical distributions. 
In such a way, by using a statistical method, such as the Monte Carlo Method (Besuner, 1987; Hammersley \& Handscomb, 1983), all the parameter distributions can be managed and each simulated 'event' can be considered as a possible 'event'. So, the computer simulation of the fatigue life of a big amount of components and the evaluation of the real risk level are possible, making this approach extremely useful.

The Authorities are interested in this approach but, before allowing the use of it as a design criterion, they require impartial evidence, first of all about the reliability of the analytical models used for fatigue simulation and for parameter distribution evaluation.

This paper intends to show a computer code - PISA, Probabilistic Investigation for Safe Aircrafts - and how it can be applied to the fatigue design of typical aerospace components, such as riveted joints, making it possible to integrate damage tolerance and the evaluation of the real risk level connected to the chosen inspection plan, (Cavallini et al., 1997; Cavallini \& R. Lazzeri, 2007).

\section{The parameters that mainly affect the fatigue phenomenon}

A metallic component subjected to repeated loads can fail due to the fatigue phenomenon, (Schijve, 2001). Many research activities on this subject are known from both the theoretical and the experimental points of view and it is well known that fatigue has a random behaviour, with a high number of parameters (mechanical behaviour of the material, loads, geometry, manufacturing technologies, etc.) that can affect it.

Almost all these parameters have a statistical behaviour, but some among them play a more important role compared to the others and must be taken into account with their distributions, while the others can be assumed to be constant.

In detail, we can assume four main parameters as statistically distributed:

- the Initial Fatigue Quality (IFQ), described by using the (Equivalent) Initial Flaw Size, (E)IFS, or the Time To Crack Initiation, TTCI, distribution, (Manning et al., 1987);

- $\quad$ the crack grow rate, CGR (constant $\mathrm{C}$ in the Paris law);

- the fracture toughness $\mathrm{K}_{\mathrm{Ic}}$, and

- the inspection reliability, i.e. the Probability of crack Detection, PoD.

They are described in the following.

\subsection{The Initial Fatigue Quality (IFQ)}

Structural components can have, until the end of the manufacturing process, defects due to metallurgical effects, scratches, roughness, inclusions, welding defects, etc.

So, the IFQ can be considered as a property linked to the material and the manufacturing process. Defects can be the starting point for fatigue cracks. For this reason it is extremely important to know their position and size, but, as they are very small, they are very difficult to be measured even if by using very sophisticated inspection methods.

As a consequence, this information can be reached only through an indirect evaluation by means of a 'draw-back' procedure starting from experimental data about detectable cracks. 
Therefore, a 'tool' able to characterize the component initial condition is necessary, in order to predict the fatigue life. At present, two approaches are available, Fig. 1:

- the (Equivalent) Initial Flaw Size distribution,

- the Time To Crack Initiation distribution.

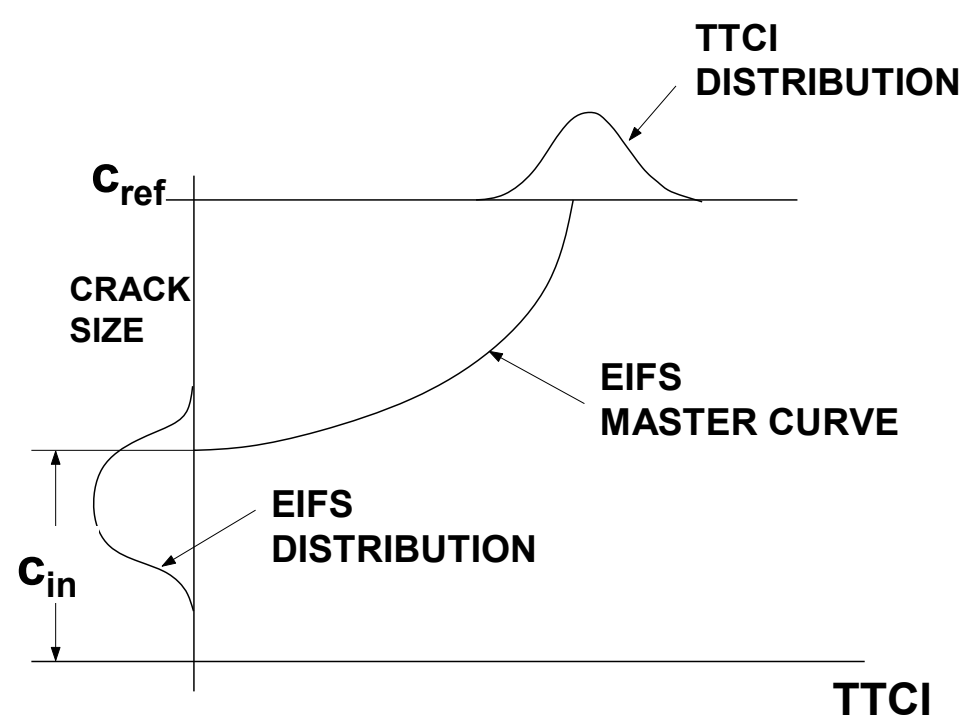

Fig. 1. TTCI and EIFS distributions.

\subsubsection{The Time To Crack Initiation distribution (TTCI)}

The TTCI model can be used to describe fatigue crack nucleation in metallic components. It can be defined as the time (in cycles, flights or flight hours) necessary for an initial defect to grow to a detectable reference crack, $c_{\text {ref. }}$ In such a way, this method does not reveal the crack dimension during the early steps of the component life. The TTCI can be described by using a Weibull, (Manning et al., 1987), or a lognormal distribution (Liao \& Komorowski, 2004). It must be noted that the TTCI distribution is not only a material property, as it is connected to the crack growth, and so to the loading fatigue spectrum.

\subsubsection{The (Equivalent) Initial Flaw Size distribution (EIFS)}

The EIFS is the (fictitious) dimension of a crack at time $t=0$. The use of the adjective 'equivalent' indicates that the initial flaw is not the actual one and its size is only 'equivalent' to it because it is very difficult to account for the influence of all the relevant parameters. The distribution can be numerically obtained starting from experimental crack size data by using a 'fictitious' backward integration of the crack growth. It is affected by the material properties and the stress distribution: cold-working, rivet interference, ... have to be taken into account, too. 
The EIFS can be described by using a lognormal or a Weibull (Manning et al., 1987) distribution. In the present paper, a lognormal distribution is assumed.

\subsection{The Crack Growth Rate, CGR (C constant in the Paris law)}

Different models are available to describe the crack growth law according to Linear Elastic Fracture Mechanics and the distribution of the involved parameters. We assumed to use the simple and effective Paris law $\mathrm{d} c / \mathrm{d} N=\mathrm{C}(\Delta K)^{\mathrm{m}}$. The parameter $m$ is assumed to be constant and all the scatter is consolidated in $\mathrm{C}$, which is assumed to belong to a normal distribution.

\subsection{The Fracture Toughness $\mathrm{K}_{\mathrm{Ic}}$}

Fracture toughness is a very important material property because it identifies a failure criterion (crack instability). Unfortunately, few experimental data are available to characterize its distribution. Anyway, a normal distribution (Hovey et al., 1991), or a lognormal distribution (Johnson, 1983; Schutz, 1980) can be supposed. We assumed the fracture toughness can be described through a lognormal distribution.

\subsection{The Probability of crack Detection (PoD)}

Non destructive inspections are among the principal items of the damage tolerance methodology. Indeed, during inspection, it is supposed that cracks are detected and the component can be re-qualified for further use. This action depends on many parameters, included the human factor and so it can be described only by using a probabilistic approach. Usually, (Lincoln, 1998), we define the inspection capability as the $90 \%$ probability of crack detection with the $95 \%$ of confidence.

Many distributions have been proposed for the Probability of Detection, (Tong, 2001; Ratwani, 1996).

In the present work we assumed a three parameters Weibull distribution, [Lewis et al., 1978]:

$$
P o D=1-e^{-\left[\frac{c-c_{\min }}{\lambda-c_{\min }}\right]^{\beta}}
$$

where, $c_{\text {min }}$ is the minimum detectable crack size, $c$ is the actual crack size and $\lambda$ and $\beta$ are parameters connected to the chosen inspection method.

\section{The Monte Carlo method}

A tool is necessary to manage all the parameter distributions together and at the same time. Some reliable approaches are available - FORM (First Order Reliability Method), SORM (Second Order Reliability Method) and many others (Madsen et al., 1986) - but we decided to use the Monte Carlo method because of its simplicity and effectiveness, as it can handle high numbers of different distributions for the stochastic variables to simulate many different deterministic situations. In addition, the Monte Carlo method easily allows the introduction of the repairs, that is a non-continuous change in the crack size. 
The Monte Carlo method is based on a very easy assumption: the probability of an event $p_{\mathrm{f}}-$ in the present paper the component failure - is evaluated by using the analytical expression

$$
p_{f}=n / N
$$

where $N$ is the total simulation number and $n$ is the number of positive results.

Each simulation reproduces only one deterministic event, in which, for each deterministic or random variable a value is assumed; for the stochastic parameters, the value is randomly obtained from its distribution.

After a high number of trials, the method converges to the solution.

The only disadvantage of this method is that it requires a high number of simulations to have a low probability of the event. As an example, if the required probability is $10^{-6}$, with a confidence level of $95 \%$, at least (Grooteman, 2002)

$$
N_{\text {trials }}>\frac{3}{10^{-6}}=3 \times 10^{6}
$$

are necessary.

\section{The PISA code and the simulation of the fatigue phenomenon}

The PISA code (Cavallini et al., 1997; Cavallini \& R. Lazzeri, 2007), developed at the Department of Aerospace Engineering of the University of Pisa, allows the simulation of the whole fatigue life of typical aerospace components, such as simple plane panels, riveted lapjoint panels, Fig. 2, or stiffened panels, subjected to constant amplitude fatigue loading.

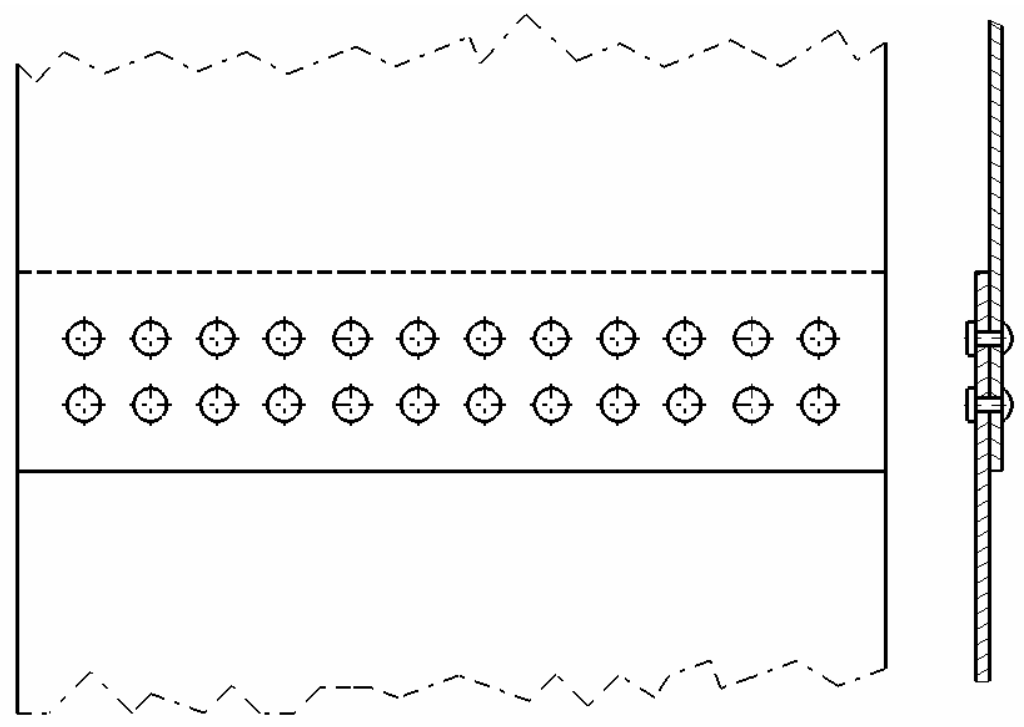

Fig. 2. Riveted lap-joint panel. 
As far as the panel is concerned, the following hypotheses can be made:

\begin{tabular}{|c|c|}
\hline \multirow{4}{*}{ Geometrical } & Plane panel \\
\cline { 2 - 3 } & Uniform thickness \\
\cline { 2 - 3 } & Constant rivet pitch \\
\cline { 2 - 3 } & Rivets with or without countersunk head \\
\cline { 2 - 2 } & Through cracks \\
\cline { 2 - 2 } & Cracks on one or both hole sides and orthogonal to the load direction \\
\cline { 2 - 2 } & Uniform stress \\
\cline { 2 - 2 } & Plane stress \\
\cline { 2 - 2 } & Uniform pin load in the same row \\
\cline { 2 - 2 } & Rivets with extremely high stiffness \\
\cline { 2 - 2 } & Fretting and corrosion effects are negligible \\
\hline
\end{tabular}

Table 1. Assumed geometrical and physical hypotheses.

The code can simulate crack nucleation, growth, inspection actions and failures in components subjected to uniform loading. The basic idea is that the damage process can be simulated as the continuous growth of an initial defect due to metallurgical effects and/or the manufacturing process, and/or other parameters.

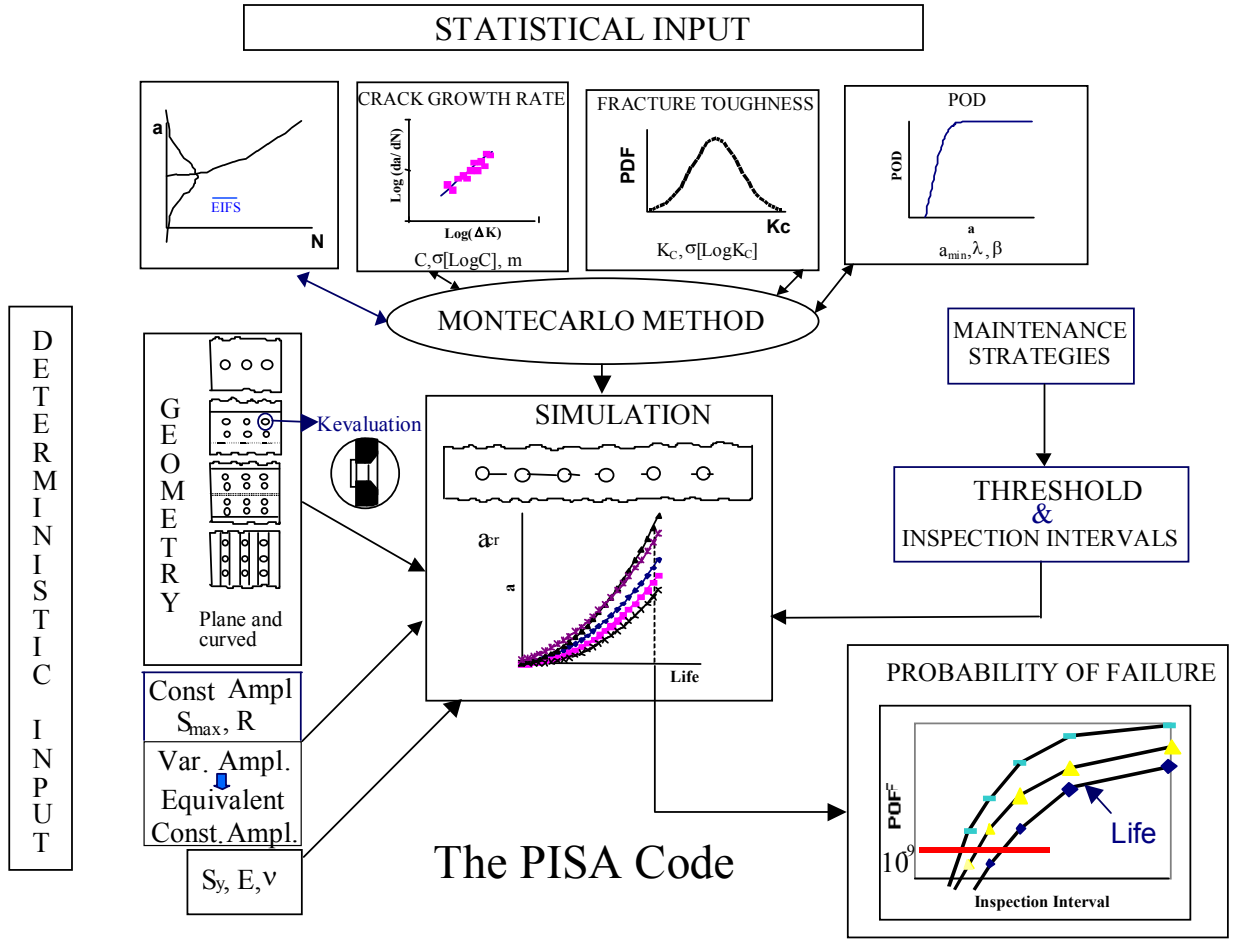

Fig. 3. Structure of the code. 
Many deterministic simulations can be run and the risk assessment can be evaluated by using the Monte Carlo method, Fig. 3. In each simulation, the deterministic parameters are assigned by taking off a value from their own distributions.

The first phase - crack nucleation at holes - is simulated by using the EIFS distribution, which can be considered as an indication of the initial fatigue quality. In this context, this approach has to be preferred to the TTCI, as it allows to consider the whole life as the only propagation phase.

The second phase - crack growth - is simulated by using the simple, well-known Paris law $\mathrm{d} c / \mathrm{d} N=\mathrm{C}(\Delta K)^{\mathrm{m}}$

The core for the evaluation of the crack growth is the expression of the stress intensity factor $K$ from the beginning of the life to the final failure.

In the stress intensity factor evaluation, suitable corrective factors (Sampath \& Broek, 1991; Kuo et al., 1986) have been used to take into account the different boundary conditions, and the load transfer inside the joints has been simulated by using the Broek \& Sampath model, (Sampath \& Broek, 1991).

In detail, the effect of different boundary conditions can be taken into account by using the composition approach (Kuo et al., 1986).

$K$ is analytically evaluated by means of a corrective coefficient which has been found by splitting the complex geometry into simple problems (open hole, finite width, ...), whose solutions are known.

With regard to the open hole

$$
\begin{gathered}
K=K^{R} \cdot C R_{1} \cdot C R_{2} \cdot C R_{n} \\
K^{R}=S \sqrt{\pi(c-r)}
\end{gathered}
$$

where $S$ is the uniform membrane stress and $(c-r)$ the crack length, Fig. 4.

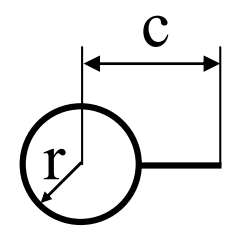

Fig. 4. Crack at an open hole.

As to the rivet effect, the load $P$ on the hole has been approximated with a uniform pressure $p$ on the hole, (Kuo et al., 1986), Fig. 5.

$$
P=t \cdot \int_{0}^{\pi} p \cdot \operatorname{sen} \theta \cdot r \cdot d \theta=t \cdot p \cdot r \cdot \int_{0}^{\pi} \operatorname{sen} \theta \cdot d \theta=2 \cdot p \cdot r \cdot t
$$




$$
p=\frac{P}{2 \cdot r \cdot t}
$$

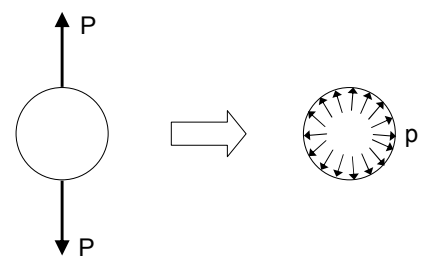

Fig. 5. Approximation of the $P$ load with a uniform pressure $p$.

$$
\begin{gathered}
K=K^{P} \cdot C P_{1} \cdot C P_{2} \cdots C P_{n} \\
K^{P}=p \sqrt{\pi c}
\end{gathered}
$$

The main corrective factors for open holes and for filled holes taken into account are summarized in Table 2.

\begin{tabular}{|c|c|}
\hline $\begin{array}{c}\text { Crack at a hole (Kuo et al., } \\
\text { 1986), }\end{array}$ & $\begin{array}{c}\text { Two cracks at a hole (Kuo et } \\
\text { al., 1986), }\end{array}$ \\
\hline $\begin{array}{c}\text { Link-up, with one crack (Kuo } \\
\text { et al., 1986), }\end{array}$ \\
$\begin{array}{c}\text { Link-up, with two cracks } \\
\text { (Kuo et al., 1986), }\end{array}$ \\
\hline $\begin{array}{c}\text { Edge crack (Kuo et al., 1986), } \\
\text { Panel finite width (Kuo et al., } \\
\text { 1986), }\end{array}$ \\
\hline $\begin{array}{c}\text { Countersink (Kuo et al., } \\
\text { 1986), }\end{array}$
\end{tabular}

Table 2. The main corrective factors for open holes and for filled holes taken into account in the PISA code. 
The Broek \& Sampath model joins the solutions related to the open hole and the loaded hole by using the superposition approach, Fig. 6.
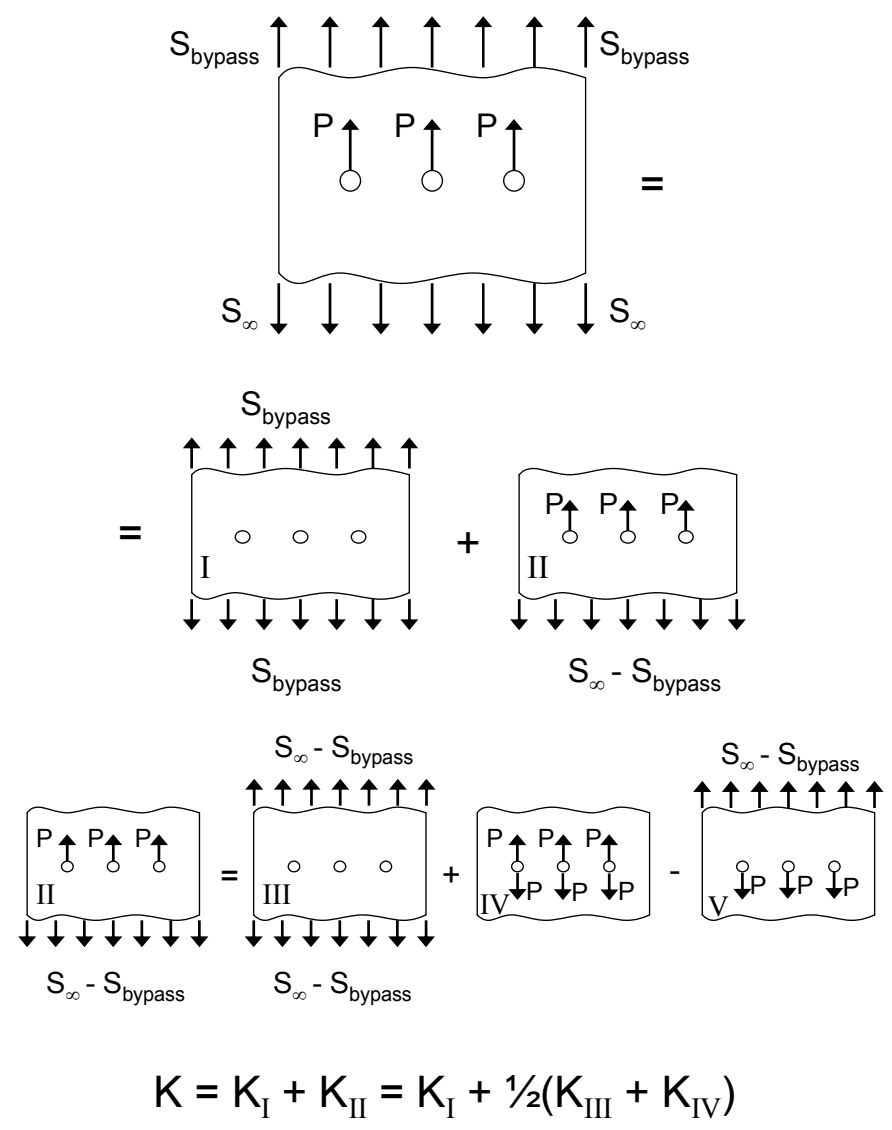

Fig. 6. The Broek \& Sampath model.

$$
K=\frac{1}{2} \cdot C R \cdot\left(S_{\infty}+S_{\text {bypass }}\right) \cdot \sqrt{\pi \cdot c}+\frac{1}{2} \cdot C P \cdot p \cdot \sqrt{\pi \cdot c}
$$

$S_{\infty}$ is the membrane uniform stress and $S_{\text {bypass }}$ is the bypass stress, i.e. for each row, the stress not transferred by the rivets.

Also rivet interference introduces an additional stress distribution. Its main effect is that only a part of the applied load amplitude $S_{\max }-S_{\min }$ is effective for crack propagation. This effect can be taken into account by using the Wang model (Wang, 1988) for the evaluation of the lift-off stress $S_{\mathrm{o}}$, corresponding to the separation of the rivet from the hole, and then by introducing in the simulations carried out with the PISA code only the effective amplitude $S_{\max }-S_{\mathrm{o}}$ for crack propagation.

Once the stress intensity factor is calculated, crack growth simulation can start. 
Two collinear cracks are considered as linked according to the Swift criterion, i.e. when their plastic radii $r_{\mathrm{p}}$ - evaluated by using the Irving expression - are tangential.

Inspections at planned intervals are simulated through the PoD distribution, applied at each crack at both hole sides. Though the repair of the hole has the same quality as the pristine panel, the repair itself of the detected crack is not immune from the possibility of having some tiny cracks.

The final failure can happen either for crack instability $\left(K_{\max }\right.$ higher than the fracture toughness, $K_{\max } \geq K_{\mathrm{Ic}}$ ) or for static failure $\left(S_{\max }\right.$ higher than the yield stress in the net section evaluated without the plastic zones, $\left.S_{\max } \geq S_{02}\right)$

\section{Experimental activity as a support for the evaluation of the statistical distributions}

To support this activity, all the parameter statistical distributions and the coefficients for the used analytical law (for example, the EIFS distribution, $C$ and $m$ coefficients for the Paris law, etc.) have to be experimentally evaluated. Of course, they cannot be obtained from tests on real components, but we have tested realistic simple specimens and we have demonstrated the applicability of the obtained results to the life evaluation of the actual components.

In this paper the activity carried out to find the distributions of the EIFS and the C constant in Paris law are shown. A similar approach can be used for the definition of the distributions for $K_{\text {Ic }}$ and PoD.

\subsection{Equivalent Initial Flaw Size distribution evaluation}

For the evaluation of the EIFS distribution it was necessary to use a 'fictitious' negative integration (draw-back) which, starting from the experimental crack data at assigned number of cycles, would be able to find the 'equivalent' initial size, i.e. the crack size at $N=0$.

To support this approach, a wide experimental activity was performed on 29 simple strip lap-joints, Fig. 7, in aluminum alloy 2024-T3 (Cavallini \& R. Lazzeri, 2007). They were fatigue tested under a constant amplitude load spectrum with $S_{\max }=120 \mathrm{MPa}$ and $R=0.1$. The tests were stopped at a set number of cycles, the specimens were statically broken and the crack dimensions were carefully measured. The tests confirmed an already well known result: all the cracks were found in the most critical location, i.e. in the first row, at the countersunk side.

At present, several numerical codes are available to simulate the growth of a single crack in the long crack range, but few can manage also the short crack range and none is able to carry out a direct negative integration that starting from the experimental crack data can find the initial dimension. For this reason, we decided to use the PISA code itself and the simplified model of a specimen with a through crack at a lap-joint, taking into account the effects of countersink of the hole, membrane stress, by-pass loading and pin load, Fig. 8, (Cavallini \& R. Lazzeri, 2007). 


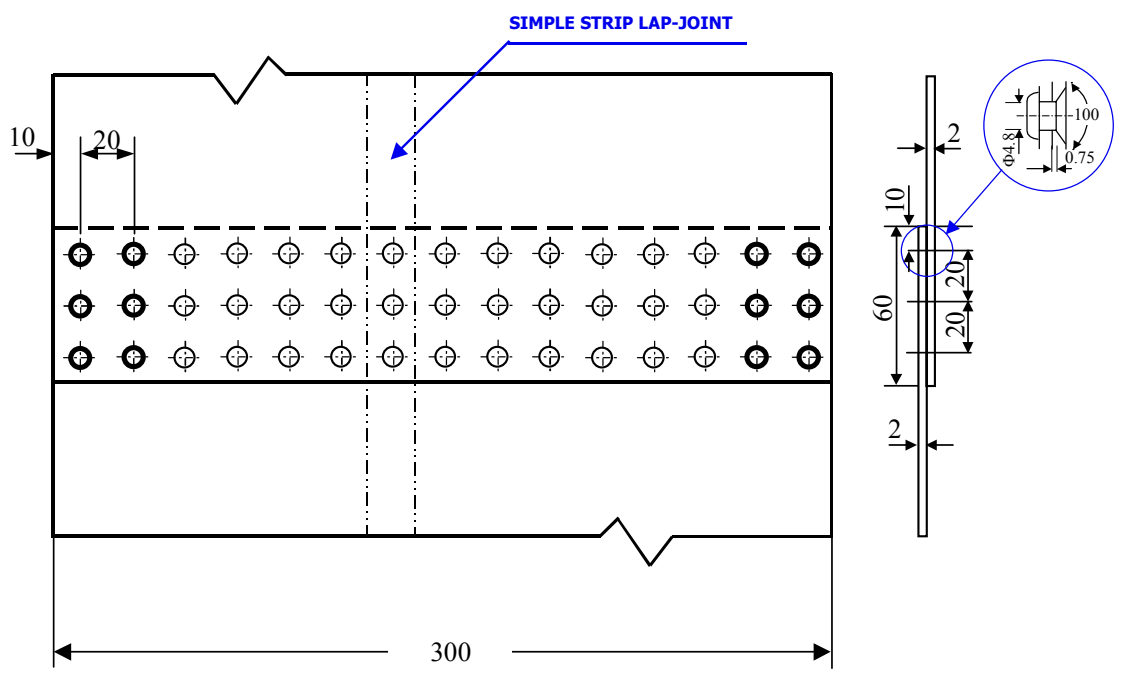

Fig. 7. Specimen geometry, all lengths in $\mathrm{mm}$.

ACTUAL MODEL

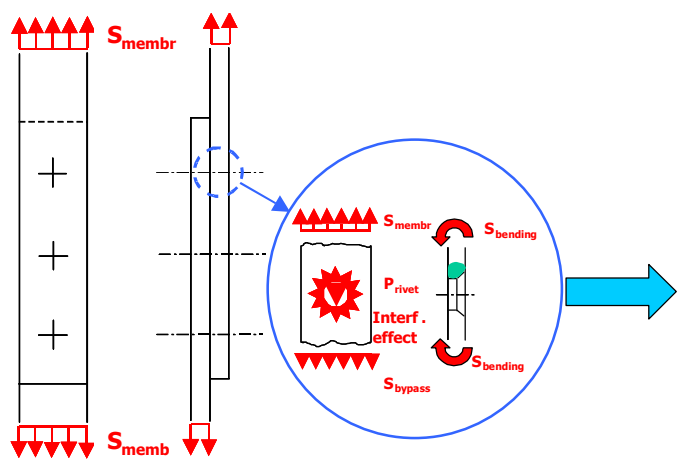

SIMPLIFIED MODEL

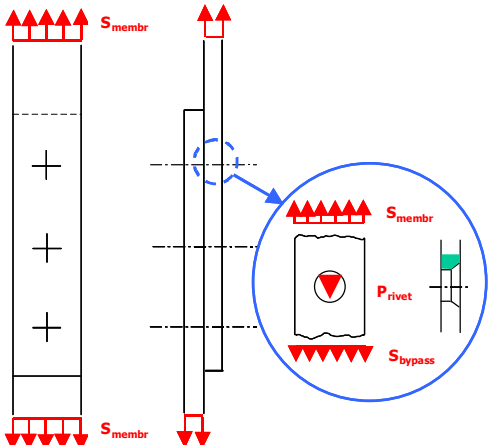

Fig. 8. Simplified model implemented inside the PISA code in order to evaluate the EIFS distribution.

In addition, an iterative positive integration was carried out starting from an initial tentative crack size value and stopping at the same number of cycles of the experimental result. The simulated final crack dimension was compared with the experimental one, and an iterative process was carried out to the required convergence.

In this way, a lognormal distribution for the EIFS was found, with $\mu\left[\log _{10}\left(c_{0}\right)\right]=-2.88605$, and $\sigma\left[\log _{10}\left(c_{0}\right)\right]=0.28456$, Fig. 9 . 


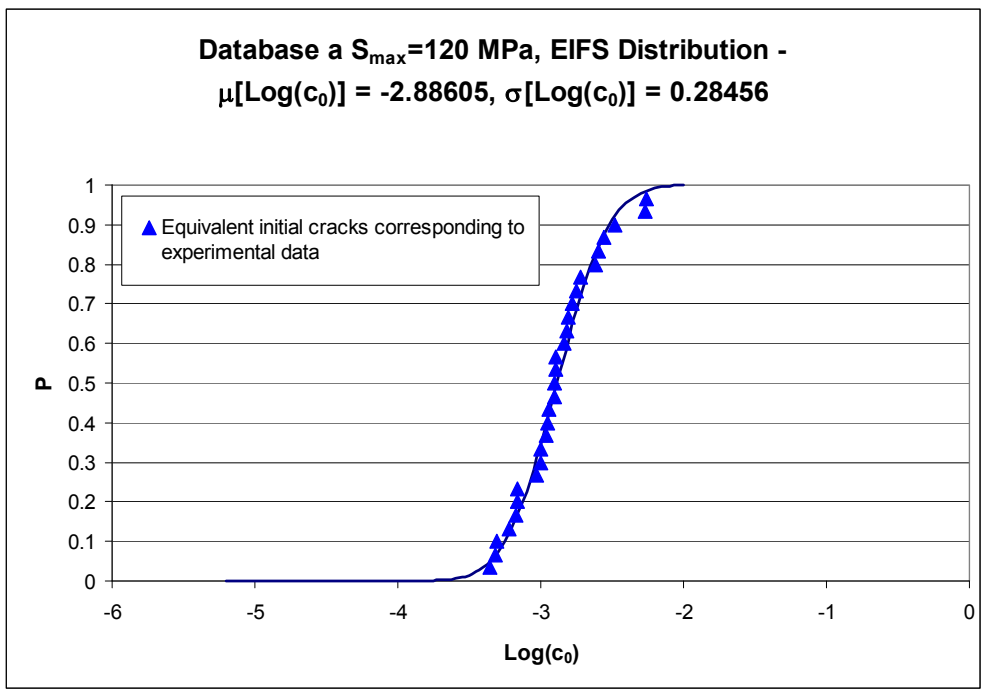

Fig. 9. EIFS distribution obtained by using the draw-back procedure.

\subsection{The Crack Growth Rate (CGR) (C constant in the Paris law)}

The crack growth law must be experimentally characterized, in order to evaluate the parameters involved in the selected crack growth law (Paris).

For their evaluation, a test campaign on a $2.1 \mathrm{~mm}$ thick Center Crack Tension (CCT) specimen with an open hole (4 mm in diameter) in aluminium alloy 2024-T3 was carried out (Imparato \& Santini, 1997), Fig. 10.

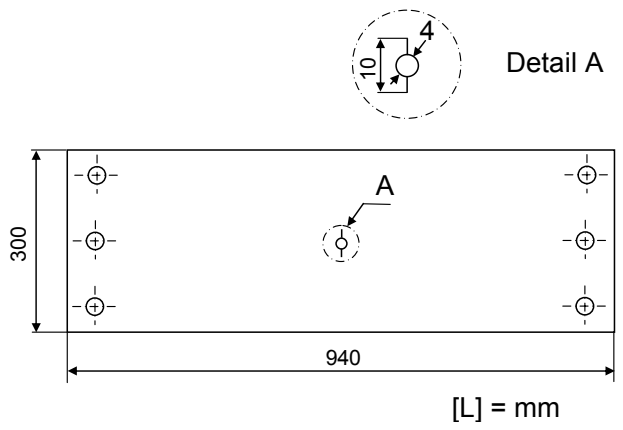

Fig. 10. CCT specimen in $\mathrm{Al} 2024-\mathrm{T} 3$.

They were pre-cracked and the further crack propagation in the 5 to $40 \mathrm{~mm}$ range was investigated by using the Potential Drop Technique.

Tests were carried out under a constant amplitude (C.A.) spectrum, at the same $S_{\max }=68.7$ MPa, with 4 different $R=S_{\min } / S_{\max }$ values $(R=0.1, R=0.25, R=0.4, R=0.55)$. In Fig. 11 the experimental results for one test are shown. 


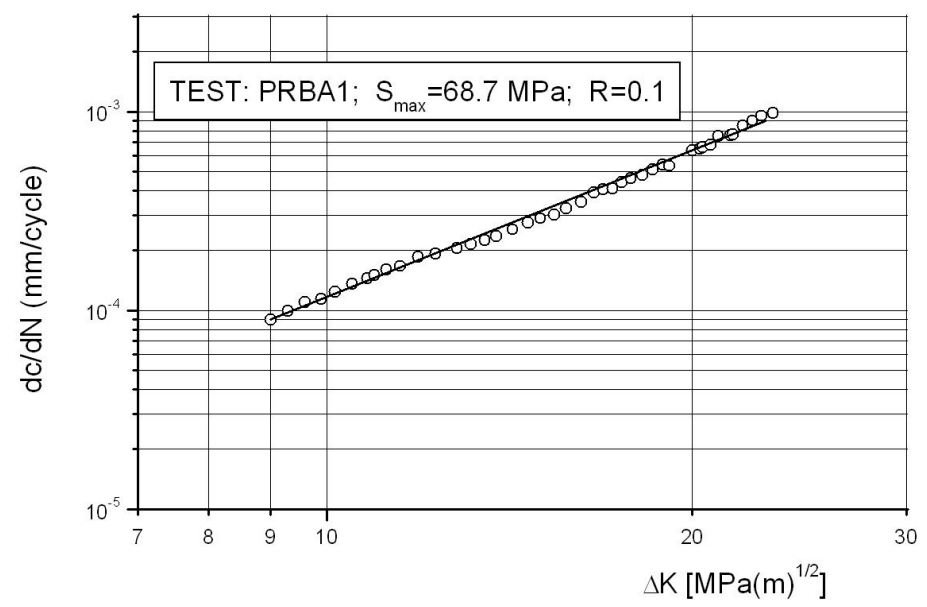

Fig. 11. Result for one CCT coupon test.

The test results were elaborated splitted for the different $\mathrm{R}$ values. For the characterization of the linear portion of the curve, we assumed $m$ as a deterministic parameter (equal for each test, Fig. 12), and we considered only $C$ as normal distributed.

In such a way, for $R=0.1$, we found that $m=2.555$ and $C$ is normal distributed with $\mu[(C)]=2.8834 \times 10^{-7}$, and $\sigma[(C)]=0.036792$.

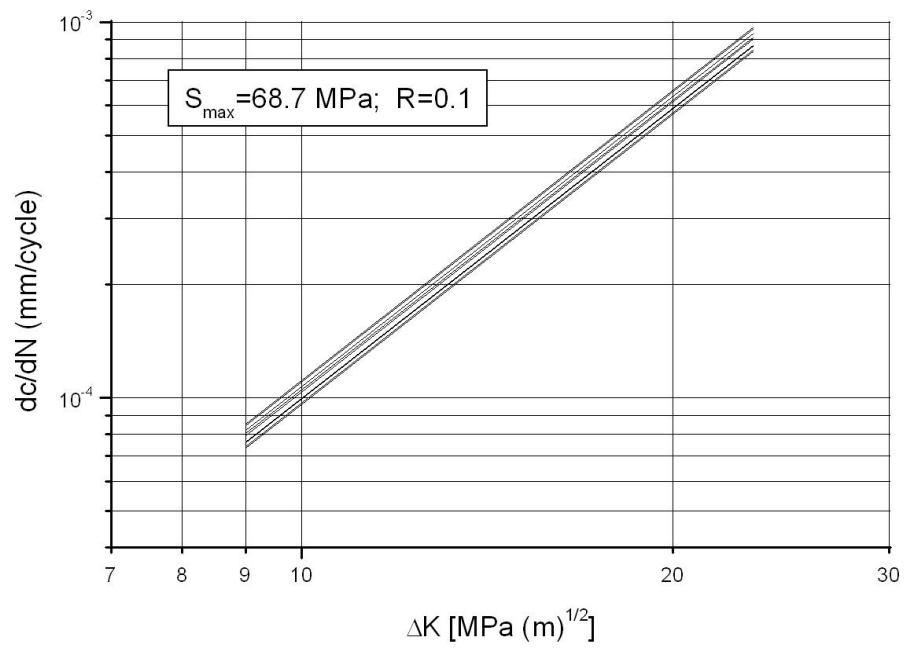

Fig. 12. Elaboration of the results for the tests at the same $R$ value.

\subsection{The validation of the analytical models implemented inside the PISA code}

To validate the approach and to verify the capability of the PISA code to simulate the fatigue behavior of aerospace structural components, further experimental tests were carried out on 
wide lap-joint panels, in the same aluminum alloy as the simple strips, Fig. 7, loaded under a constant amplitude spectrum $\left(S_{\max }=120 \mathrm{MPa}, R=0.1\right)$.

A group of panels was fatigue tested for an assigned number of cycles ( 1 at 70,000 cycles, 4 at 75,000 cycles, 4 at 80,000 cycles, 3 at 85,000 cycles) and then statically broken to measure the sizes of the nucleated cracks. Also, in these panels the cracks were found only in the most critical row, i.e. the first one, at the countersunk side.

After having statically broken the tested panels, it was not possible, at all the hole sides, to detect a crack and they were considered as run-outs. The run-out effect has been introduced inside the crack size distribution by using the maximum likelihood method (Spindel \& Haibach, 1979). Their crack dimensions have been supposed less than $0.1 \mathrm{~mm}$. We supposed that the crack sizes (both with and without the run-outs) belong to two lognormal distributions.

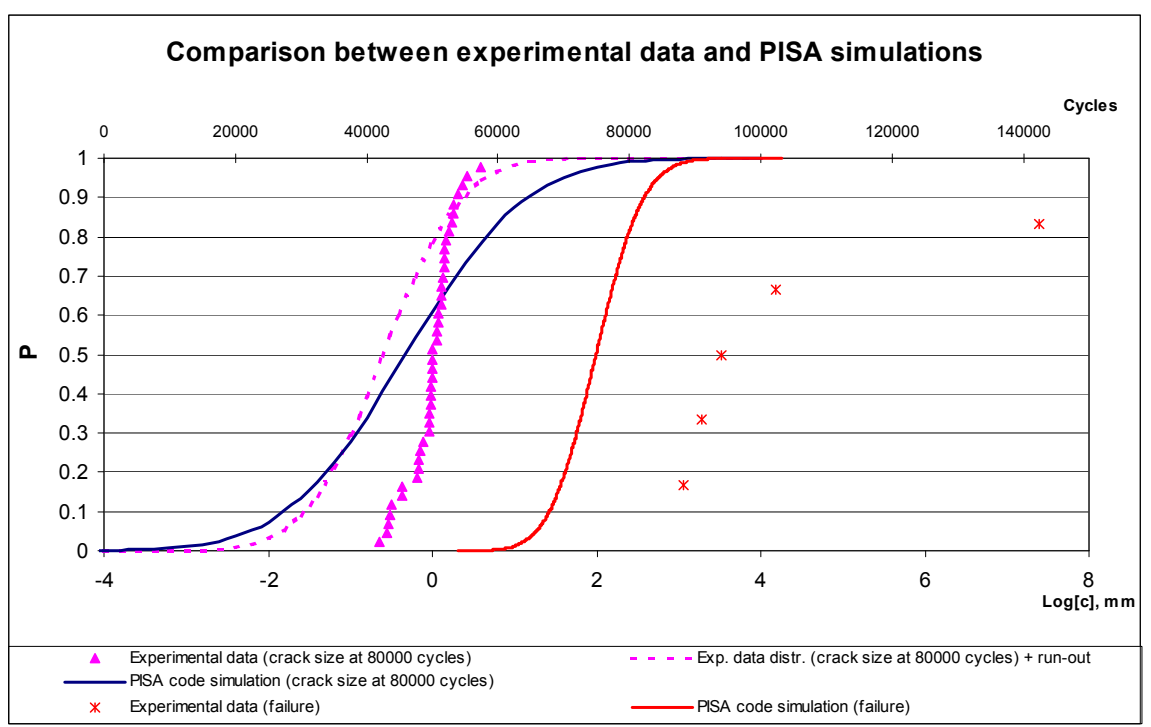

Fig. 13. Comparison between experimental data and PISA simulations (crack dimensions at 80,000 cycles and cycles to failure for the lap-joint panels).

Starting from the EIFS distribution obtained by the simple strip joints and by using the PISA code, the capability of the procedure has been verified by simulating the behavior of the cracks in the most critical row of the lap-joint panels.

The comparison has been made by generating 1000 runs, i.e. by simulating the crack sizes at different number of cycles in the most critical row of 1000 lap-joint panels similar to the tested lap-joint panels (i.e. 15 holes $\times 2$ sides $=30$ positions for each panel). In Figure 13 (Cavallini \& R. Lazzeri, 2007) the comparison is shown between the predicted crack dimensions and the corresponding experimental results at 80,000 cycles. 
The agreement between predictions and experimental results can be seen; in detail, the predicted distribution obtained by using PISA is included between the experimental data distribution with and without the run-outs, Fig. 13.

In addition, 5 further lap-joint panels were fatigue tested till failure. In Fig. 13 the comparison between PISA simulations and the experimental results is also shown. The agreement is good, though the simulation results are a little conservative.

\section{Applications of the PISA code}

The Pisa code is organized in such a way that all the information about geometry, material characterization, loads, inspection methods, failure criteria are collected in an input file.

The code can be used for the evaluation of the fatigue behaviour of only one component, starting from an initial known crack path, or for the generation of high numbers of deterministic simulations for the probabilistic approach.

\subsection{The simulation of a single panel}

In Fig. 14, the fatigue behaviour of a very simple panel, with only four open holes (diameter $=4 \mathrm{~mm}$ ), in $\mathrm{Al} 2024-\mathrm{T} 3$, loaded under a constant amplitude load with $S_{\max }=100$ $\mathrm{MPa}$ and $R=0.1$, is simulated. The initial crack path is extracted from the EIFS distribution, but it would be assigned also as an external input. The assigned life was 100,000 cycles. Inspections were planned every 25,000 cycles. For the probability of detection parameters, we assumed $c_{\min }=0.65 \mathrm{~mm}, \lambda=1.62 \mathrm{~mm}, \beta=1.35$, (extrapolated from Ratwani, 1996).

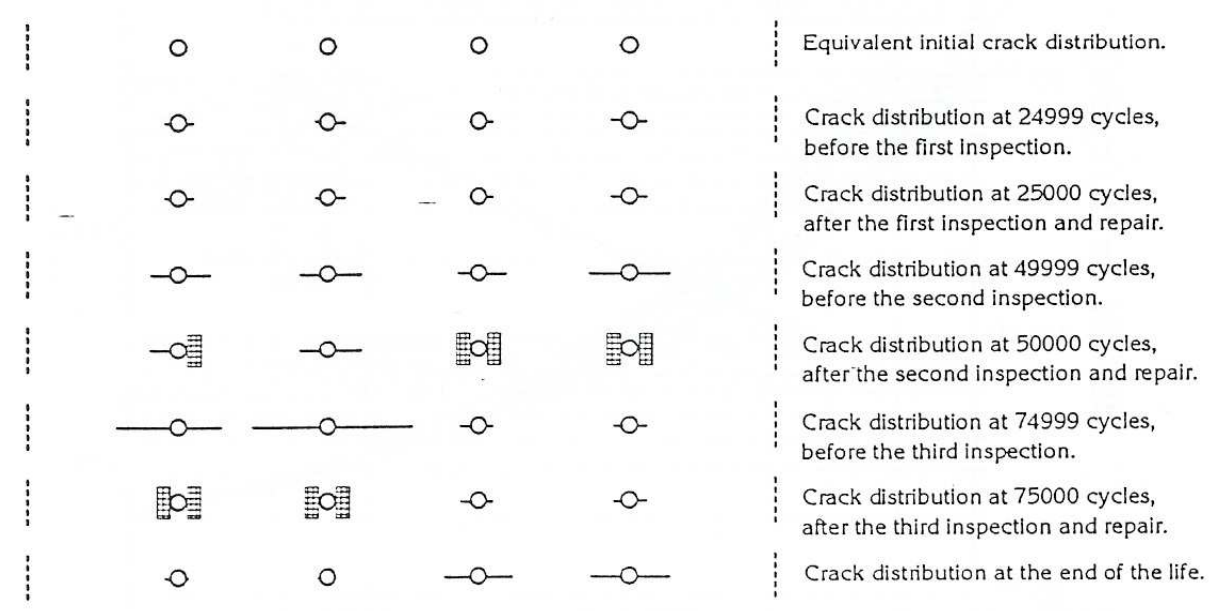

Fig. 14. Simulation of the fatigue life of an open hole panel (damage tolerance criterion).

As it can be seen in the Figure, during the first inspection (at 25,000 cycles) cracks were too small and were not detected. They grew till the second inspection (at 50,000 cycles), when 
five cracks were detected and the panel repaired. The simulation went on till the following inspection, when four more cracks were detected and repaired. With this inspection plan the panel could reach the target life.

\subsection{Applications of the PISA code for the probabilistic risk evaluation}

Before applying the Pisa code for the evaluation of the probability of failure of an aerospace component, an acceptable risk level must be identified. Indeed, one among the most debated items connected with the application of this methodology is the definition of the 'acceptable' risk level. Usually, 'risk' defines the probability of failure of some components within an assigned period.

Lincoln (Lincoln, 1998), says that for the USAF an acceptable global risk failure is $10^{-7}$ for flight, even if other authors suggest a safer $r(\mathrm{t}) \leq 10^{-9}$ per hour (Lundberg, 1959).

We fixed $r(\mathrm{t}) \leq 10^{-7}$. To reach a $10^{-7}$ probability of failure, at least $3 \times 10^{+7}$ simulations must be run.

Starting from a lap-joint in Al 2024-T3, Fig. 7, loaded at C.A. with $S_{\max }=120 \mathrm{MPa}, R=0.1$, our aims were the definition of a 'safe' maintenance plan, the comparison of the effects of the deterministic (safe-life and damage tolerance) and the probabilistic approaches, and the evaluation of their respective advantages and disadvantages, (Cavallini \& R. Lazzeri, 2007).

We assumed the following distributions for the stochastic parameters:

- The EIFS fits a lognormal distribution, with $\mu\left[\log _{10}\left(c_{0}\right)\right]=-2.88605$, and $\sigma\left[\log _{10}\left(c_{0}\right)\right]=0.28456,\left[c_{0}\right]$ in $\mathrm{mm}$.

- $\quad$ The $C$ parameter in the Paris law is normal distributed, with $\mu[(C)]=2.8834 \times 10^{-7}$, and $\sigma[(C)]=0.036792$. The corresponding $m$ value is $m=2.555$.

- The fracture toughness $K_{\text {Ic }}$ fits a lognormal distribution, with $\mu\left[\log _{10}\left(K_{\text {Ic }}\right)\right]=1.65$ (Koolloons, 2002), and COV $=\sigma\left[\log _{10}\left(K_{\mathrm{Ic}}\right)\right] / \mu\left[\log _{10}\left(K_{\mathrm{Ic}}\right)\right]=0.14,\left[K_{\mathrm{Ic}}\right]=\mathrm{MPa}(m)^{0.5}$ (Schutz, 1980),

- $\quad$ The probability of detection is expressed as (1), with $c_{\min }=0.65 \mathrm{~mm}, \lambda=1.62 \mathrm{~mm}, \beta=1.35$, (extrapolated from Ratwani, 1996).

At first, we simulated the fatigue behaviour of $3 \times 10^{+7}$ lap-joint panels without any inspection actions. The number of cycles with probability of failure equal to $10^{-7}$ is 51,000 cycles, Fig. 15. So, this number of cycles can be fixed for the first inspection (threshold).

The second run was made after having fixed, for each panel, the first inspection at 51,000 cycles. In such a way, we obtained the new probability of failure curve and it was possible to fix the second inspection at 63,000 cycles, that is $(63,000-51,000)=12,000$ cycles after the first one.

In Fig. 15 the probability of failures corresponding to the different deterministic approaches are also shown.

The safe life criterion requires the component replacement after a portion (as for example $1 / 4$ ) of its mean life. The mean life (probability of failure equal to $50 \%$ ) corresponds to 74,550 cycles that, divided by four, gives 18,638 cycles. So, for the safe life criterion, after 18,638 
cycles the component should be substituted, without any consideration about its real damage condition.

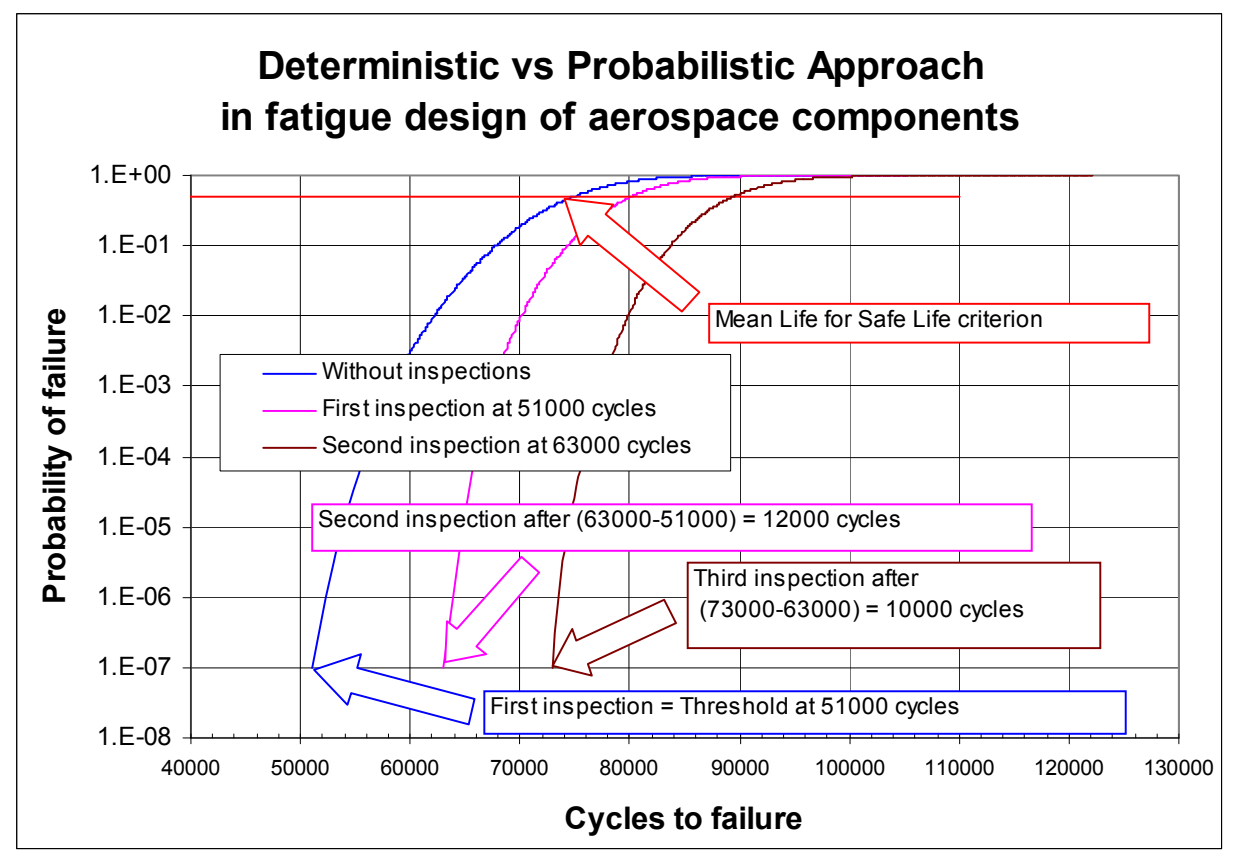

Fig. 15. Example of PISA simulation and maintenance strategy for a lap-joint panel.

The probability of failure at 18,638 cycles is extremely low, so the component could still be used without any loss in safety. In this situation, the component replacement only introduces costs.

As far as the damage tolerance criterion is concerned, the first inspection (threshold) is fixed by evaluating the number of cycles necessary for a crack of assigned dimension (regulations state a $1.27 \mathrm{~mm}$ size) to grow till the final failure. The inspections cited below are planned considering the propagation period of a sure visible crack (depending on the selected inspection method, in this case $6.35 \mathrm{~mm}$ ) till the final failure. A safety factor equal to 2 at the threshold and 3 at the following period are additionally applied.

For this component, by analytical calculation or by using the PISA code itself, it can be found that the period necessary for a crack to grow from $1.27 \mathrm{~mm}$ to the final failure is equal to 57,700 cycles, and from $6.35 \mathrm{~mm}$ to the final failure is equal to 31,100 cycles.

Therefore, the first inspection will be carried out at $57,700 / 2=28,850$ cycles and the next one after $31,100 / 3=10,367$ cycles.

As it can be seen in Fig 15, the corresponding probability of failures is very low, and so the inspection plan, based on the deterministic damage tolerance approach, might be very expensive. 


\section{Conclusion}

In this Chapter, a new possible and useful approach to fatigue design of aerospace metallic components is explained, founded on probabilistic bases, together with a tool - the PISA code - and the experimental test results used for the validation of the tool, and of the approach.

The validation analysis provided good results and therefore the PISA code can be used for the risk assessment analysis and to compare the effect of the deterministic approaches (damage tolerance and safe-life) with those of the probabilistic approach in the fatigue design of a wide lap-joint panel.

The advantages appeared to be very significant:

- $\quad$ the probability of failure can be defined as a design constraint (or goal), for instance $10^{-7}$; so the risk level is well defined. In deterministic approaches, this important element is not known and the assumption of conservative values of the inputs can produce uneconomical designs without benefits;

- in each design condition, it is possible to know the "distance" from the critical condition in terms of probability of failure;

- $\quad$ the Multiple Site Damage event can be handled in a logical way because it is one of the possible statistical events. The same problem, faced on deterministic bases, could bring to heavy and/or very expensive solutions;

- components are inspected or withdrawn and substituted only if really necessary, thus avoiding too early inspections or the substitution of intact components.

The comparison between the different approaches, applied to a lap joint panel, shows that a more economic inspection plan can be applied if the probabilistic approach is used, without loss of safety.

Of course, this new methodology can be safely applied only if reliable models for the crack growth are available, and the parameter distributions have been carefully obtained.

\section{References}

Besuner P.M. (1987). Probabilistic Fracture Mechanics, In: Probabilistic fracture mechanics and reliability, Provan Ed., pp. 387-436, Martinus Nijhoff Publ., ISBN 90-247-3334-0, Dordrecht (NL).

Cavallini G., Lanciotti A. \& Lazzeri L. (1997). A Probabilistic Approach to Aircraft Structures Risk Assessment, Proceedings of the 19th ICAF Symposium, Edinburgh (UK), June 1997, pp. 421-440.

Cavallini G. \& Lazzeri R. (2007). A probabilistic approach to fatigue risk assessment in aerospace components. Eng. Fracture Mech., vol. 74, issue 18, (Dec. 2007), pp. 29642970.

Federal Aviation Administration (1998). Federal Aviation Regulations - Part 25. Airworthiness Standards: Transport Category Airplanes, Section 571, Damagetolerance and fatigue evaluation of structures. Available from http://rgl.faa.gov/Regulatory_and_Guidance_Library/rgFAR.nsf/Frameset?Ope nPage 
Grooteman F. P. (2002). WP4.4: Structural Reliability Solution Methods - Advanced Stochastic Method, Admire Document N. ADMIRE-TR-4.4-03-3.1/NLR-CR-2002-544.

Hammersley J. M. \& Handscomb D. C. (1983). Monte Carlo Methods, Chapman and Hall Publ., ISBN 0-412-15870-1, New York.

Hovey P. W., Berens A. P. \& Skinn D. A. (1991). Risk Analysis for Aging Aircraft Volume 1 Analysis, Flight Dynamics Directorate, Wright Laboratory, Wright-Patterson AFB, OH 45433-6553.

Imparato G. \& Santini L. (1997). Prove sperimentali sul comportamento a fatica di strutture con danneggiamento multiplo, Thesis in Aeronautical Engineering, Department of Aerospace Engineering, University of Pisa.

Joint Aviation Authorities (1994). Joint Airworthiness Requirements, JAR-25, Large Aeroplanes, Section 1, Subpart D, JAR 25.571, Damage-tolerance and fatigue evaluation of structures.

Johnston G. O. (1983). Statistical scatter in fracture toughness and fatigue crack growth rates, In: Probabilistic fracture Mechanics and Fatigue Methods: Applications for structural design and maintenance, ASTM STP 798, pp. 42-66, Bloom J.M. \& Ekvall J.C., American Society for Testing Materials.

Koolloons M. (2002). Details on Round Tobin Tests, ADMIRE Document, ADMIRE-TR-5.104-1.1/NLR.

Kuo, A., Yasgur, D. \& Levy, M. (1986). Assessment of damage tolerance requirements and analyses - Task I report., ICAF Doc. 1583, AFVAL-TR-86-3003, vol. II, AFVAL Wright-Patterson Air Force Base, Dayton, Ohio.

Lewis W. H., Sproat W.H., Dodd B. D. \& Hamilton J. M. (1978). Reliability of nondestructive inspection-final report, San Antonio Air Logistic Center, Rep. SA-ALC/MME 76-6-381.

Liao M. \& Komorowski J. P. (2004). Corrosion risk assessment of aircraft structures. Journal of ASTM International, vol. 1, no. 8 (September 2004), pp. 183-198.

Lincoln J.W. (1998). Role of nondestructive inspection airworthiness assurance, RTO AVT Workshop on Airframe Inspection Reliability under field/depot conditions, Brussels, Belgium, May 1998.

Lundberg, B. (1959). The Quantitative Statistical Approach to the Aircraft Fatigue Problem, Full-Scale Fatigue Testing of Aircraft Structures, Proceedings of the 1st ICAF Symposium, Amsterdam, Netherlands, 1959, Pergamon Press, pp. $393-412$ (1961).

Madsen H. O., Krenk S. \& Lind N. C. (1986). Methods of Structural Safety, Prentice Hall, Inc., ISBN 0-13-579475-7, Englewood Cliffs, NJ.

Manning, S.D., Yang, J.N. \& Rudd, J.L. (1987). Durability of Aircraft Structures, In: Probabilistic Fracture Mechanics and Reliability, Provan J.W. (ed.), pp. 213-267, Martinus Nijhoff.

Ratwani M. M. (1996). Visual and non-destructive inspection technologies, In: Aging Combat Aircraft Fleets - Long Term Implications, AGARD SMP LS-206.

Sampath S. \& Broek D. (1991). Estimation of requirements of inspection intervals for panels susceptible to multiple site damage, In: Structural Integrity of Aging Airplanes, Atluri S.N., Sampath, S.G. \& Tong, P., Editors, , pp. 339-389, Springer-Verlag, Berlin.

Schijve J., (2001). Fatigue of Structures and Materials, Kluwer Academic Publishers, ISBN 07923-7013-9, Dordrecht, NL. 
Schutz W. (1980). Treatment of scatter of fracture toughness data for design purpose, In: Practical Applications of fracture Mechanics, AGARD-AG-257, Liebowitz H. (ed).

Spindel J.E. \& Haibach E. (1979). The method of maximum likelihood applied to the statistical analysis of fatigue data. International Journal of Fatigue, vol. I, no. 2, (April 1979), pp. 81-88.

Tong Y. C. (2001). Literature Review on Aircraft Structural Risk and Reliability Analysis, Department of Defence DSTO, Melbourne. Available from http://dspace.dsto.defence.gov.au/dspace/bitstream/1947/4289/1/DSTO-TR$1110 \% 20$ PR.pdf

US Department of Defence (1998). Joint Service Specification Guide - Aircraft Structures, JSSG-2006, Available from http://www.everyspec.com/USAF/USAF+(General)/JSSG-2006_10206/.

Wang G. S. (1988). An Elastic-Plastic Solution for a Normally Loaded Center Hole in a finite Circular Body, Int. J. Press-Ves E Piping, vol. 33, pp. 269-284. 


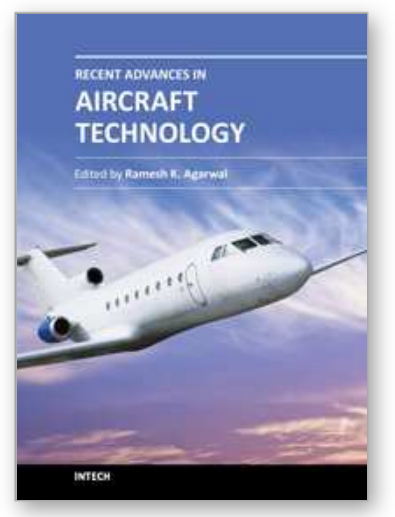

\author{
Recent Advances in Aircraft Technology \\ Edited by Dr. Ramesh Agarwal
}

ISBN 978-953-51-0150-5

Hard cover, 544 pages

Publisher InTech

Published online 24, February, 2012

Published in print edition February, 2012

The book describes the state of the art and latest advancements in technologies for various areas of aircraft systems. In particular it covers wide variety of topics in aircraft structures and advanced materials, control systems, electrical systems, inspection and maintenance, avionics and radar and some miscellaneous topics such as green aviation. The authors are leading experts in their fields. Both the researchers and the students should find the material useful in their work.

\title{
How to reference
}

In order to correctly reference this scholarly work, feel free to copy and paste the following:

Giorgio Cavallini and Roberta Lazzeri (2012). A Probabilistic Approach to Fatigue Design of Aerospace Components by Using the Risk Assessment Evaluation, Recent Advances in Aircraft Technology, Dr. Ramesh Agarwal (Ed.), ISBN: 978-953-51-0150-5, InTech, Available from: http://www.intechopen.com/books/recentadvances-in-aircraft-technology/a-probabilistic-approach-to-fatigue-design-of-aerospace-components-byusing-the-risk-assessment-eval

\section{INTECH}

open science | open minds

\section{InTech Europe}

University Campus STeP Ri

Slavka Krautzeka 83/A

51000 Rijeka, Croatia

Phone: +385 (51) 770447

Fax: +385 (51) 686166

www.intechopen.com

\section{InTech China}

Unit 405, Office Block, Hotel Equatorial Shanghai

No.65, Yan An Road (West), Shanghai, 200040, China

中国上海市延安西路65号上海国际贵都大饭店办公楼 405 单元

Phone: +86-21-62489820

Fax: +86-21-62489821 
(C) 2012 The Author(s). Licensee IntechOpen. This is an open access article distributed under the terms of the Creative Commons Attribution 3.0 License, which permits unrestricted use, distribution, and reproduction in any medium, provided the original work is properly cited. 